\title{
Comparative study of phytochemicals and antioxidant potential of wild edible mushroom caps and stipes
}

\author{
Bárbara Ribeiro a, Rosário Lopes a, Paula B. Andrade a , Rosa M. Seabra a , Rui F. Gonçalves a , \\ Paula Baptista ${ }^{b}$, Inês Quelhas ${ }^{a}$, Patrícia Valentão ${ }^{a, *}$ \\ ${ }^{\text {a }}$ REQUIMTE/Serviço de Farmacognosia, Faculdade de Farmácia, Universidade do Porto, R. Aníbal Cunha, 164, 4050-047 Porto, Portugal \\ ${ }^{\mathrm{b}}$ CIMOIEscola Superior Agrária, Instituto Politécnico de Bragança, Quinta de Sta Apolónia, Apartado 1172, $5301-855$ Bragança, Portugal
}

Received 30 July 2007; received in revised form 17 December 2007; accepted 28 January 2008

\begin{abstract}
A comparative study of the organic acids and phenolics composition and of the total alkaloids content of entire wild edible mushrooms (Russula cyanoxantha, Amanita rubescens, Suillus granulatus and Boletus edulis) and correspondent caps and stipes was performed. All species presented oxalic, citric, malic and fumaric acids, with A. rubescens exhibiting the highest total organic acids content. Organic acids were preferably fixed in the cap. Among phenolics, only $p$-hydroxybenzoic acid was found in $A$. rubescens and $S$. granulatus, in very low amounts. B. edulis was the species that presented the highest total alkaloid amounts. Except for this species, alkaloids mainly accumulated in the cap. All of the species exhibited a concentration-dependent scavenging ability against DPPH'. B. edulis revealed the highest antioxidant capacity. The cap seemed to be the part with highest antioxidant potential. Some relationships between chemical composition and antioxidant capacity were considered.
\end{abstract}

(c) 2008 Elsevier Ltd. All rights reserved.

Keywords: Wild edible mushrooms; Alkaloids; Phenolic compounds; Organic acids; Antioxidant potential

\section{Introduction}

Mushrooms have been used as food and food-flavouring material in soups and sauces for centuries, due to their unique and subtle flavour. The occurrence of high amounts of proteins, carbohydrates and fibres and low fat contents is often referred in the literature in relation to their nutritional value. Furthermore, they have significant levels of vitamins, namely thiamine, riboflavin, ascorbic acid and vitamin D2, as well as minerals (Mattila, Suonpaa, \& Piironen, 2000). Regarding their medicinal value, mushrooms are effective as antitumor, antibacterial, antiviral and haematological agents and in immunomodulating treatments (Wasser \& Weis, 1999; Yang, Lin, \& Mau, 2002).

\footnotetext{
${ }^{*}$ Corresponding author. Tel.: +351 222078935; fax: +351 222003977. E-mail address: valentao@ff.up.pt (P. Valentão).
}

Mushroom species have been shown to possess antioxidant capacity in in vitro systems (Ribeiro et al., 2006, Ribeiro, Valentão, Baptista, Seabra, \& Andrade, 2007). Like other matrices containing antioxidant compounds, e.g. phenolics (Bendini et al., 2006; Quezada, Ascensio, Del Valle, Aguilera, \& Gómez, 2004), organic acids (Mato, Huidobro, Simal-Lozano, \& Sancho, 2003) and alkaloids (Quezada et al., 2004), mushrooms can be used both as a food supplement and in the pharmaceutical industry.

The Trás-os-Montes region (northeast of Portugal) is recognized as one of the richest regions of Europe in wild edible mushroom species, of considerable gastronomic relevance. Russula cyanoxantha, Amanita rubescens, Suillus granulatus and Boletus edulis are among the more common and eaten species.

A previous study on carboxylic and phenolic compounds and their antioxidant activity has been reported by Ribeiro et al. (2006). In addition, the antimicrobial 
capacity of tetraprenylphenols isolated from $S$. granulatus is described in the literature (Tringali, Piattelli, Geraci, \& Nicolosi, 1989). However, these works were performed with the entire mushroom. Nothing seems to be reported for alkaloids determination.

The aim of this work was to perform a comparative study of the fundamental parts, cap and stipe, of $R$. cyanoxantha, A. rubescens, S. granulatus and B. edulis species.

\section{Materials and methods}

\subsection{Standards and reagents}

Oxalic, citric, ketoglutaric, malic, succinic, quinic, shikimic, fumaric and $p$-hydroxybenzoic acids, boldine, bismuth (III) nitrate pentahydrate and 1,1-diphenyl-2-picrylhydrazyl were purchased from Sigma (St. Louis, MO, USA). Methanol and nitric, hydrochloric, sulphuric, formic and glacial acetic acids were obtained from Merck (Darmstadt, Germany). Potassium iodide and sodium hydroxide were from Pronalab (Lisboa, Portugal). Thiourea and sodium sulphide $x$-hydrate were purchased from Panreac Quimica Sau (Barcelona, Spain). Iron(III) chloride was purchased from Riedel-de Haën (Seelze, Germany). The water was treated in a Milli-Q water purification system (Millipore, Bedford, MA, USA).

\subsection{Samples}

Samples of the four different wild edible mushrooms species were collected from orchards of Quercus pyrenaica or Pinus pinaster, in the Bragança region (northeast Portugal) (Table 1).

After harvesting, the mushrooms were immediately transferred to the laboratory. Taxonomic identification followed those done by several authors (Bas et al., 1990-2001; Bon, 1988; Courtecuisse, 1999; Courtecuisse and Duhem, 1995; Marchand, 1971; Moser, 1983) and representative voucher specimens were deposited at the herbarium of Escola Superior Agrária of Instituto Politécnico de Bragança. Samples were dehydrated in a ventilated stove at $30^{\circ} \mathrm{C}$, for 5 days, and then caps and stipes were separated. Entire mushrooms were also used for comparisons. The different materials were kept in the dark, in hermetically sealed bags prior to analysis. All materials were crushed and passed through a $910 \mu \mathrm{m}$ screen.

\subsection{Extraction of phenolics, organic acids and alkaloids}

For the chemical characterization and for antioxidant activity assay, $10 \mathrm{~g}$ of each powdered sample were boiled in $500 \mathrm{ml}$ of water for $30 \mathrm{~min}$ and then filtered through a Büchner funnel. The resulting extract was lyophilized in a Labconco 4.5 Freezone apparatus (Kansas City, MO, USA), at $-45^{\circ} \mathrm{C}$ and $33 \times 10^{-3} \mathrm{mbar}$, for 6 days. The lyophilized extracts were kept in an exsicator, in the dark.

\subsection{HPLC analysis of organic acids}

The lyophilized extract was redissolved in $0.01 \mathrm{~N}$ sulphuric acid and $20 \mu \mathrm{l}$ were analyzed as previously reported (Ribeiro et al., 2006), in a system consisting of an analytical HPLC unit (Gilson), in conjunction with a column heating device set at $30^{\circ} \mathrm{C}$, with an ion exclusion column, Nucleogel $^{\circledR}$ Ion $300 \mathrm{OA}(300 \times 7.7 \mathrm{~mm})$. Elution was carried out isocratically with sulphuric acid $0.01 \mathrm{~N}$, at a solvent flow rate of $0.2 \mathrm{ml} / \mathrm{min}$. The detection was performed with a UV detector set at $214 \mathrm{~nm}$.

Organic acids quantification was achieved by the absorbance recorded in the chromatograms relative to external standards, and the peaks in the chromatograms were integrated using a default baseline construction technique.

\subsection{Phenolic compounds screening tests}

Lyophilized extract $(0.25 \mathrm{~g})$ were redissolved in $2 \mathrm{ml}$ of water and $20 \% \mathrm{NaOH}$ and $4.5 \% \mathrm{FeCl}_{3}$ were added to two aliquots of the resulting solution.

\subsection{HPLC analysis of phenolics}

For phenolic compounds analysis, the lyophilized extract was redissolved in water and $20 \mu \mathrm{l}$ of the resulting solution were analyzed using an analytical HPLC unit (Gilson), with a Spherisorb ODS2 $(25.0 \times 0.46 \mathrm{~cm}$; $5 \mu \mathrm{m}$, particle size) column (Valentão et al., 2005a). The solvent system was a mixture of water-formic acid (19:1) (A) and methanol (B). Elution was performed at a flow rate of $0.9 \mathrm{ml} / \mathrm{min}$ and the gradient was as follows: $5 \% \mathrm{~B}$ at $0 \mathrm{~min}, 15 \% \mathrm{~B}$ at $3 \mathrm{~min}, 25 \% \mathrm{~B}$ at $13 \mathrm{~min}, 30 \% \mathrm{~B}$ at $25 \mathrm{~min}, 35 \% \mathrm{~B}$ at $35 \mathrm{~min}, 45 \% \mathrm{~B}$ at $39 \mathrm{~min}, 45 \% \mathrm{~B}$ at $42 \mathrm{~min}, 50 \% \mathrm{~B}$ at $44 \mathrm{~min}, 55 \% \mathrm{~B}$ at $47 \mathrm{~min}, 70 \% \mathrm{~B}$ at $50 \mathrm{~min}, 75 \% \mathrm{~B}$ at $56 \mathrm{~min}$ and $80 \% \mathrm{~B}$ at $60 \mathrm{~min}$. Detection was achieved with a Gilson diode array detector. Spectral data from all peaks were accumulated in the $200-400 \mathrm{~nm}$ range and the chromatograms were recorded at $280 \mathrm{~nm}$ for $p$-hydroxybenzoic acid. Data were processed using the Gilson Unipoint system and peak purity was checked by the software contrast facilities. The peaks in the chromatograms were integrated using a default baseline construction technique.

\subsection{Total alkaloids}

\subsubsection{General}

The total alkaloid contents were determined by a spectrophotometric method, in which the alkaloids were precipitated by Dragendorff's reagent, following a described procedure (Sreevidya \& Mehrotra, 2003), but using a different range of bismuth nitrate stock solution concentrations and omitting the washing step after alkaloids precipitation. 
Table 1

Characterization of mushroom samples

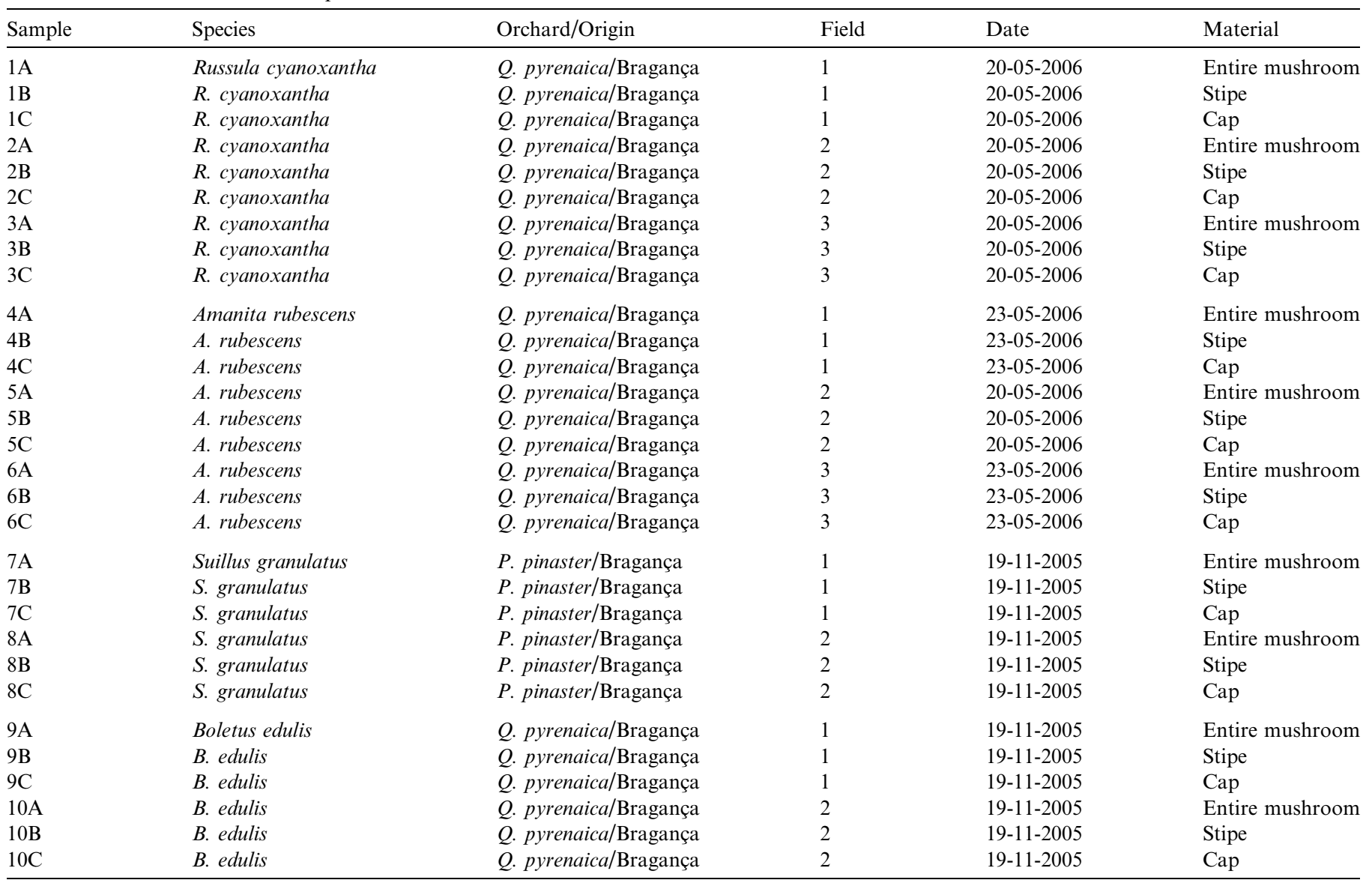

\subsubsection{Dragendorff reagent ( $D R$ )}

Bismuth nitrate $(0.8 \mathrm{~g})$ was dissolved in $40 \mathrm{ml}$ of distilled water and $10 \mathrm{ml}$ of glacial acetic acid. The resulting solution was mixed with $20 \mathrm{ml}$ of $40 \%$ potassium iodide.

\subsubsection{Calibration curve}

A bismuth nitrate stock solution was prepared by dissolving $18.4 \mathrm{mg}$ of bismuth nitrate in $5 \mathrm{ml}$ of concentrated nitric acid and diluting to $100 \mathrm{ml}$ with distilled water. A calibration curve was obtained with diluted solutions in a concentrations series of $379,284,213,160,120,90.0$, $67.5,50.6$ and $38.0 \mu \mathrm{mol} / 1$. One $\mathrm{ml}$ of each solution was taken and $5 \mathrm{ml}$ of thiourea $3 \%$ were added. The absorbance of the yellow solution was measured at $435 \mathrm{~nm}$. The assay was performed in triplicate. The average regression equation was $y=6.83 \times 10^{-4} x$.

\subsubsection{Assay}

A stock solution of boldine was prepared by dissolving $10 \mathrm{mg}$ in warm distilled water, made up to $10 \mathrm{ml}$. For mushroom extracts, ca. $0.15 \mathrm{~g}$ of each lyophilized material was treated in the same way.

Five $\mathrm{ml}$ of boldine solution/extract were taken and adjusted to $\mathrm{pH} 2-2.5$ with $0.01 \mathrm{M} \mathrm{HCl} ; 2 \mathrm{ml}$ of DR were added and the precipitate formed was centrifuged at
$5000 \mathrm{rpm}$ for $10 \mathrm{~min}$. The centrifugate was checked for complete precipitation by further addition of DR. After centrifugation, the supernatant was discarded and the residue was treated with $2 \mathrm{ml} 1 \%$ sodium sulphide. The brownish black precipitate formed was then centrifuged at $5000 \mathrm{rpm}$ for $15 \mathrm{~min}$. Complete precipitation was assessed by further addition of $1 \%$ sodium sulphide. The residue was dissolved in $2 \mathrm{ml}$ of concentrated nitric acid, with warming and sonication. This solution was diluted to $10 \mathrm{ml}$ with distilled water; $5 \mathrm{ml}$ of thiourea $3 \%$ were added to $1 \mathrm{ml}$ of the resulting solution, and the absorbance was measured at $435 \mathrm{~nm}$. All the assays were performed in triplicate.

The amount of bismuth present in the boldine solution/ extract was determined from the calibration curve of bismuth nitrate. The results were expressed as boldine, considering that this is a monobasic alkaloid and, therefore, the complex formed with bismuth follows a 1:1 stoichiometry.

\section{8. $D P P H$-scavenging activity}

The antiradical activity of the extracts was determined spectrophotometrically in an ELX808 IU Ultra Microplate Reader (Bio-Tek Instruments, Inc.), by monitoring the disappearance of $\mathrm{DPPH}^{-}$at $515 \mathrm{~nm}$, according to a described 
procedure (Ribeiro et al., 2006). For each species, only one sample was tested, corresponding to that with the highest available amount of lyophilized extract. The reaction mixtures in each well consisted of $25 \mu \mathrm{l}$ of aqueous extract and $200 \mu \mathrm{l}$ of $150 \mathrm{mM} \mathrm{DPPH}$. The plate was incubated for 30 min at room temperature after addition of DPPH solution. Three experiments were performed in triplicate.

\subsection{Statistical analysis}

The evaluation of statistical significance was determined by ANOVA, followed by Newman-Keuls test. The level of significance was set at $p<0.05$ (95\% statistical confidence level).

\section{Results and discussion}

\subsection{Organic acids}

The organic acid profile showed that all the four species contained oxalic, citric, malic and fumaric acids. Some of them also had ketoglutaric, quinic, succinic and shikimic acids (Table 2, Fig. 1). A. rubescens presented the highest total organic acids content, followed by $R$. cyanoxantha, $S$. granulatus and B. edulis.

$R$. cyanoxantha showed a profile composed of oxalic, citric, malic, quinic and fumaric acids (Table 2). Excepting sample 2, in which the entire mushroom was the material presenting the highest total organic acids amount, it seems that these compounds accumulate mainly in the cap. In quantitative profile, the different mushroom parts are similar, presenting malic and quinic acids as the major compounds. Oxalic acid was the minor one. However, some differences were observed: the cap showed a tendency for higher concentrations of citric and quinic acids, but its malic acid content was significantly smaller than that of the stipe (Fig. 2).

In comparison with entire mushrooms, studied previously (Ribeiro et al., 2006), we observed that the samples analyzed did not present aconitic or succinic acids, but their total organic acids were higher. These differences could be due to the origin of the orchard (the previous samples were obtained from a Castanea sativa orchard) and/or to the year of collection. In addition, the samples may correspond to different maturity stages. As observed previously, malic and quinic acids were the main compounds and the sum of their relative amounts was also similar (ca. $89 \%$ of total acids).

In $A$. rubescens, oxalic, citric, ketoglutaric, malic, quinic, succinic, shikimic and fumaric acids were identified (Table 2, Fig. 1). It does not seem that organic acids are accumulated at a special part since, for each one of the three $A$. rubescens samples, the material presenting the highest organic acids contents were different: for sample 4 , the cap exhibited the highest amount while for samples 5 and 6 , it was the entire mushroom and the stipe, respectively. The cap had significantly higher citric acid contents than the stipe.
On the other hand, quinic acid concentrations were significantly higher in the stipe (Fig. 2).

When comparing with the entire mushroom of a previous work (Ribeiro et al., 2006), the organic acids profile was different because of the presence of succinic acid and the absence of aconitic and ascorbic acids in the samples now analysed. The total organic acids content was also superior to that found previously (Ribeiro et al., 2006). The major compound was now quinic acid (Fig. 2), instead of the pair malic plus quinic acids. The differences observed could be related to the samples' origin (the samples analyzed previously came from a C. sativa orchard), to the year of collection and/or to different developmental stages of the samples.

The analysis of $S$. granulatus samples allowed the identification of oxalic, citric, malic, quinic, succinic, shikimic and fumaric acids (Table 2), and the cap had the highest contents of these compounds. The analysis of the quantitative profiles obtained made it possible to acknowledge that succinic and shikimic acids were those which appeared in lower quantities and that the major compounds differed according to the different mushroom parts (Fig. 2): quinic acid in cap and fumaric and citric acids in stipe. Oxalic, malic and succinic acids presented important differences in their relative amounts in the different mushrooms.

In relation to the entire mushrooms analysed previously (Ribeiro et al., 2006), some differences were noticed, mainly at a qualitative level. The present $S$. granulatus samples did not contain aconitic, ketoglutaric or ascorbic acids. These differences could be related to distinct developmental stages of the samples and to the fact that each mushroom is a distinct individual. Neverthless, citric and quinic acids were the major compounds and shikimic acid the minor one in the entire mushroom, as observed previously.

B. edulis presented an organic acids profile composed of oxalic, citric, malic, succinic and fumaric acids (Table 2). The total organic acids was significantly higher in the cap, while stipe and entire mushrooms contained similar amounts of these compounds. These results indicate that, as in $R$. cyanoxantha and $S$. granulatus, organic acids of B. edulis species are preferably fixed in the cap. The quantitative profile (Fig. 2) showed malic acid as the major compound, whereas succinic and fumaric acids only appeared in very low amounts. Additionally, cap and stipe have a tendency to concentrate malic and citric acids, respectively.

In comparison with previous data of entire mushrooms (Ribeiro et al., 2006; Valentão et al., 2005b), we can observe that these samples do not present aconitic, ketoglutaric or quinic acids. This could be explained by the different origin (C. sativa orchard in previous work), collection date and, eventually, by the developmental stage of the mushrooms. Once more, malic acid represented the major compound.

\subsection{Phenolic compounds}

The screening tests for phenolic compounds with $\mathrm{NaOH}$ and $\mathrm{FeCl}_{3}$ revealed their occurrence in all of the analyzed 
Table 2

Organic acids content of mushroom species $(\mathrm{mg} / \mathrm{kg} \text {, dry basis })^{\mathrm{a}}$

\begin{tabular}{|c|c|c|c|c|c|c|c|c|c|}
\hline Sample & $\begin{array}{l}\text { Oxalic } \\
(R T=20.0 \mathrm{~min})\end{array}$ & $\begin{array}{l}\text { Citric } \\
(R T=28.4 \mathrm{~min})\end{array}$ & $\begin{array}{l}\text { Ketoglutaric } \\
(R T=29.5 \mathrm{~min})\end{array}$ & $\begin{array}{l}\text { Malic } \\
(R T=34.3 \mathrm{~min})\end{array}$ & $\begin{array}{l}\text { Quinic } \\
(R T=35.8 \mathrm{~min})\end{array}$ & $\begin{array}{l}\text { Succinic } \\
(R T=43.3 \mathrm{~min})\end{array}$ & $\begin{array}{l}\text { Shikimic } \\
(R T=44.2 \mathrm{~min})\end{array}$ & $\begin{array}{l}\text { Fumaric } \\
(R T=57.7 \mathrm{~min})\end{array}$ & Total \\
\hline $1 \mathrm{~A}$ & $\mathrm{nq}$ & $2310(54.8)$ & - & $44,266(0.0)$ & $36,877(0.0)$ & - & - & 7233 (246) & 90,686 \\
\hline 1B & $611(64.1)$ & $1870(118)$ & - & $44,840(497)$ & $46,158(1747)$ & - & - & 8295 (69.2) & 101,774 \\
\hline $1 \mathrm{C}$ & $\mathrm{nq}$ & $1652(68.8)$ & - & $32,335(2778)$ & $63,818(1396)$ & - & - & $6283(111)$ & 104,088 \\
\hline $2 \mathrm{~A}$ & $\mathrm{nq}$ & $5574(264)$ & - & $58,601(2437)$ & $35,249(6759)$ & - & - & 7409 (83.0) & 106,834 \\
\hline $2 \mathrm{~B}$ & 1163 & 2801 (237) & - & $42,019(0.0)$ & $43,372(0.0)$ & - & - & $5952(47.2)$ & 95,306 \\
\hline $2 \mathrm{C}$ & $\mathrm{nq}$ & $8451(275)$ & - & $31,630(100)$ & $37,848(309)$ & - & - & $6775(312)$ & 84,703 \\
\hline $3 \mathrm{~A}$ & $746(93.7)$ & $2934(57.1)$ & - & $47,088(1583)$ & $36,453(1226)$ & - & - & $7181(174)$ & 94,401 \\
\hline $3 \mathrm{~B}$ & $653(25.6)$ & $1905(116)$ & - & 32,802 (1689) & $36,363(6467)$ & - & - & $5796(292)$ & 77,519 \\
\hline $3 \mathrm{C}$ & $1060(11.8)$ & $4301(437)$ & - & $37,245(273)$ & $49,827(705)$ & - & - & $6570(30.0)$ & 99,003 \\
\hline $4 \mathrm{~A}$ & 1873 (1278) & $12,130(430)$ & 1974 (118) & 9903 (336) & $63,135(2143)$ & 127 (3.6) & $18.6(1.8)$ & 1804 (27.2) & 90,964 \\
\hline 4B & 1158 (18.8) & $4138(82.2)$ & $1867(24.8)$ & $11,155(991)$ & $110,205(1121)$ & $23.8(0.6)$ & $24.7(1.6)$ & $3064(3.3)$ & 131,634 \\
\hline $4 \mathrm{C}$ & $488(43.1)$ & $19,366(726)$ & $1524(42.1)$ & 14,309 (94.6) & $95,264(630)$ & $348(15.4)$ & $89.0(5.3)$ & $2212(6.2)$ & 133,599 \\
\hline $5 \mathrm{~A}$ & $786(67.0)$ & $10,100(337)$ & $1598(105)$ & $14,870(290)$ & $119,527(2056)$ & $150(3.1)$ & $23.4(0.6)$ & $1804(27.1)$ & 148,859 \\
\hline $5 \mathrm{~B}$ & $888(16.2)$ & $3123(350)$ & $2778(8.2)$ & $10,769(2534)$ & $124,098(2872)$ & $36.1(0.2)$ & $43.5(0.1)$ & $2656(27.4)$ & 144,392 \\
\hline $5 \mathrm{C}$ & $864(6.2)$ & $13,269(715)$ & 1571 (31.6) & 7714 (115) & $86,480(2202)$ & $280(1.8)$ & $83.1(1.5)$ & 1663 (26.9) & 111,925 \\
\hline $6 \mathrm{~A}$ & $1810(4.3)$ & $18,651(62.8)$ & $5019(887)$ & $10,554(14.7)$ & $80,068(2200)$ & $106(4.0)$ & $32.7(2.4)$ & 2307 (25.7) & 118,547 \\
\hline $6 \mathrm{~B}$ & $1137(10.8)$ & $3526(240)$ & 1967 (117) & 9435 (934) & $110,405(1404)$ & $36.1(0.2)$ & $43.5(0.1)$ & $3038(39.7)$ & 129,587 \\
\hline $6 \mathrm{C}$ & $551(26.0)$ & $13,242(839)$ & $976(12.0)$ & $11,330(329)$ & $85,479(5694)$ & $215(0.9)$ & $29.7(2.1)$ & $2861(145)$ & 114,684 \\
\hline $7 \mathrm{~A}$ & 2764 (164) & $9147(300)$ & - & $5792(341)$ & $11,389(0.0)$ & $306(10.8)$ & $\mathrm{nq}$ & $11,150(828)$ & 40,547 \\
\hline $7 \mathrm{~B}$ & $1271(127)$ & $3955(64.0)$ & - & $912(65.0)$ & $2879(433)$ & $119(2.8)$ & $\mathrm{nq}$ & 8958 (11.2) & 18,094 \\
\hline $7 \mathrm{C}$ & $1134(150)$ & $13,345(101)$ & - & 11,166 (197) & $86,444(1525)$ & $227(16.9)$ & $\mathrm{nq}$ & $2406(155)$ & 114,722 \\
\hline $8 \mathrm{~A}$ & $9746(225)$ & $17,315(561)$ & - & $8521(1082)$ & $16,203(0.0)$ & $506(9.5)$ & $\mathrm{nq}$ & $4712(30.8)$ & 57,003 \\
\hline $8 \mathrm{~B}$ & 2427 (206) & 8876 (1.09) & - & $\mathrm{nq}$ & $\mathrm{nq}$ & $70.1(2.1)$ & nq & $11,462(59.7)$ & 22,835 \\
\hline $8 \mathrm{C}$ & $2960(53.1)$ & $16,701(1337)$ & - & $13,673(2353)$ & $31,231(1575)$ & $289(14.1)$ & $\mathrm{nq}$ & $19,074(300)$ & 83,928 \\
\hline $9 \mathrm{~A}$ & $417(3.4)$ & $1175(100)$ & - & $7880(37.8)$ & - & $53.6(2.6)$ & - & $27.9(0.3)$ & 9553 \\
\hline 9B & $110(4.7)$ & $4790(121)$ & - & $7935(1.8)$ & - & $81.2(5.3)$ & - & $25.0(0.6)$ & 12,942 \\
\hline $9 \mathrm{C}$ & $1400(10.0)$ & $3157(0.6)$ & - & $32,257(1881)$ & - & $191(6.5)$ & - & $281(7.1)$ & 37,285 \\
\hline $10 \mathrm{~A}$ & $901(22.2)$ & 459 (3.6) & - & $9765(351)$ & - & $73.8(0.1)$ & - & $33.8(2.9)$ & 11,234 \\
\hline $10 \mathrm{~B}$ & $\mathrm{nq}$ & $1468(91.0)$ & - & $10,549(42.0)$ & - & $113(1.1)$ & - & $30.3(0.1)$ & 12,160 \\
\hline $10 \mathrm{C}$ & 1207 (20.9) & $2192(62.1)$ & - & 37,987 (646) & - & $73.4(5.4)$ & - & $235(1.3)$ & 41,695 \\
\hline
\end{tabular}

${ }^{a}$ Results are expressed as means (standard deviation) of three determinations. nq: not quantified. 


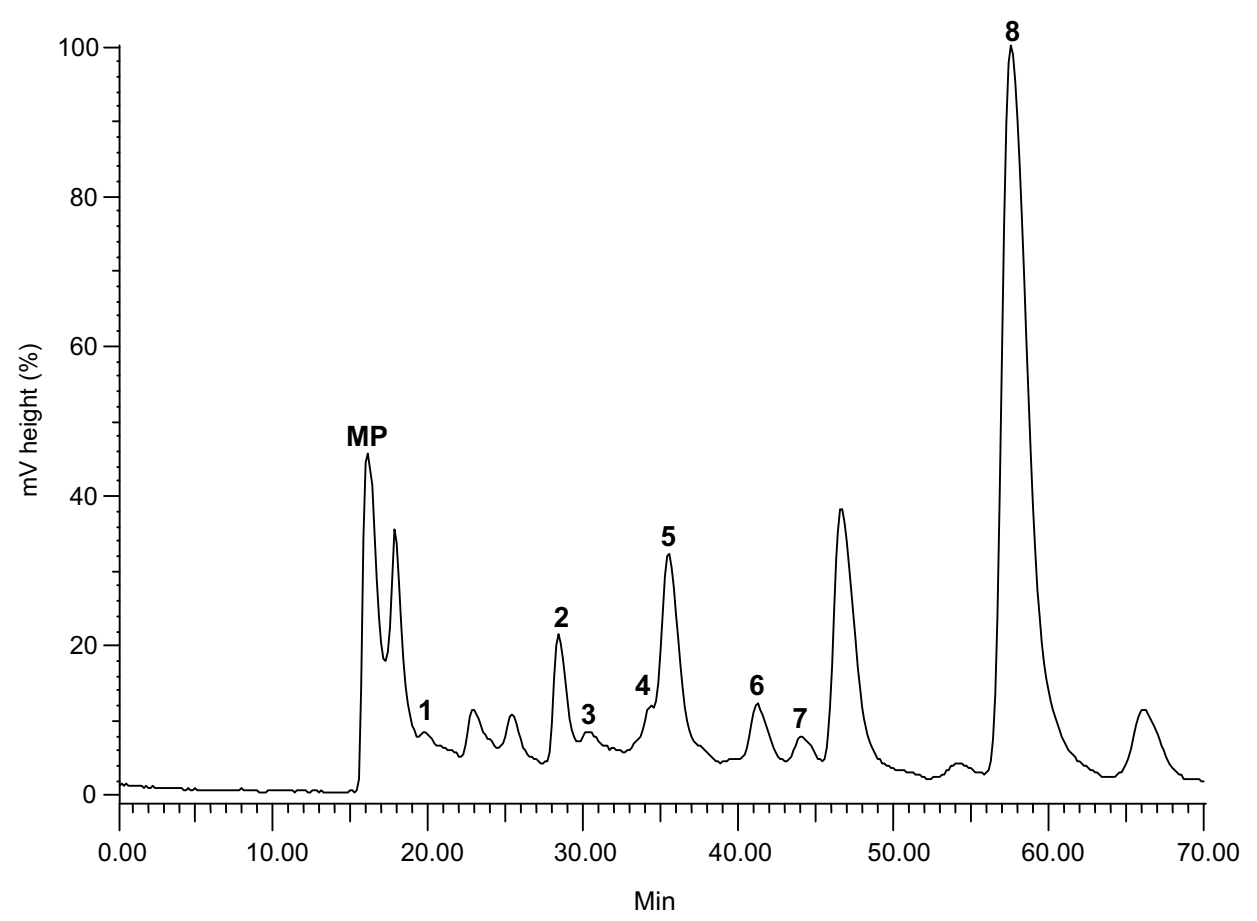

Fig. 1. HPLC organic acids profile of $A$. rubescens cap (sample 5C). Detection at $214 \mathrm{~nm}$ : (MP) mobile phase; (1) oxalic acid; (2) citric acid; (3) ketoglutaric acid; (4) malic acid; (5) quinic acid; (6) succinic acid; (7) shikimic acid; (8) fumaric acid.

\section{R. cyanoxantha}

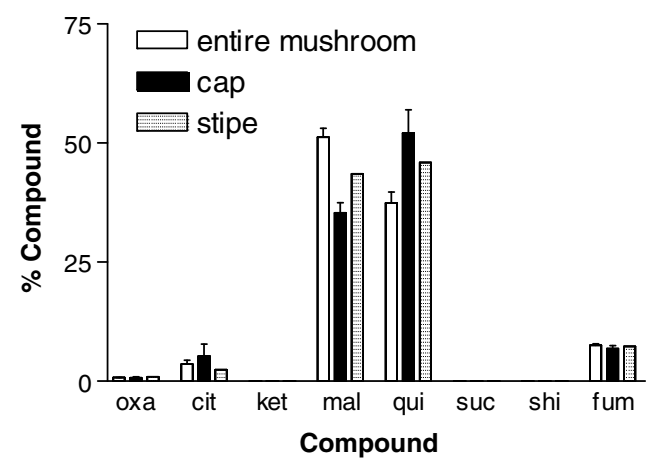

A. rubescens

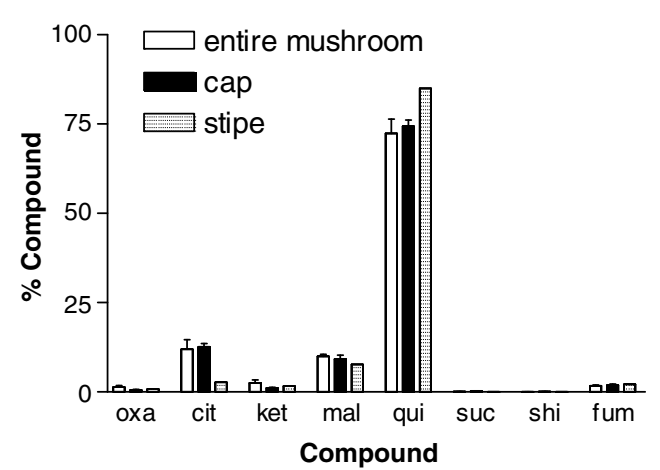

S.granulatus

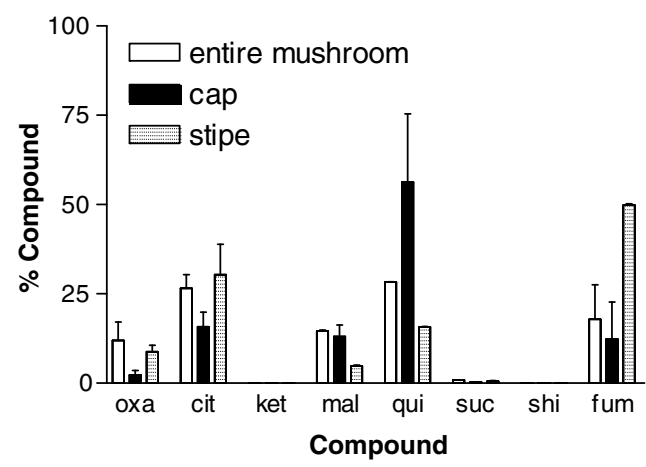

B. edulis

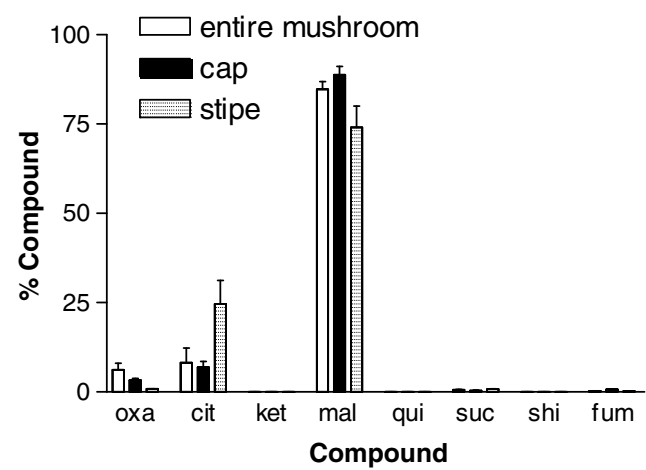

Fig. 2. Organic acids profile of edible mushrooms species. Values represent means and standard error bars are on the top of each column. Abbreviations: (oxa) oxalic acid; (cit) citric acid; (ket) ketoglutaric acid; (mal) malic acid; (qui) quinic acid; (suc) succinic acid; (shi) shikimic acid; (fum) fumaric acid.

species. These compounds are scarce in wild edible mushrooms. Our previous work (Ribeiro et al., 2006) and reports on other mushrooms species (Mattila et al., 2001; Ribeiro et al., 2007; Valentão et al., 2005a) confirm low 
contents of phenolic compounds. In the present study, the HPLC analysis allowed the identification of $p$-hydroxybenzoic acid in A. rubescens and in $S$. granulatus species (Table 3 , Fig. 3). In the study with entire mushrooms of $R$. cyanoxantha (Ribeiro et al., 2006), it was possible to detect vestigial amounts of $p$-hydroxybenzoic acid. The absence of this compound in the samples now analysed may be related to the orchard of origin, collection date and/or to the developmental stage of the samples. Additionally, it was not possible to identify any phenolic compound in B. edulis species.

In $A$. rubescens, $p$-hydroxybenzoic acid was found both in samples of entire mushroom and of cap (Table 3). These results suggest that this compound may have a propensity to accumulate in the cap.

The analysis of $S$. granulatus allowed the identification of $p$-hydroxybenzoic acid in samples 7C (cap) and 8A (entire mushroom) (Table 3). The presence of this compound in the cap of sample 7 but not in the entire mushroom could be attributed to its absence in the stipe, and, therefore, it would appear less concentrated in the entire mushroom extract. This dilution could lead to such small amounts of $p$-hydroxybenzoic acid in this material that it

Table 3

Phenolic contents of mushroom species ( $\mathrm{mg} / \mathrm{kg}$. dry basis) ${ }^{\mathrm{a}}$

\begin{tabular}{|c|c|}
\hline \multirow[t]{2}{*}{ Sample } & \multirow{2}{*}{$\frac{\text { Compound }}{p \text {-Hydroxybenzoic acid }}$} \\
\hline & \\
\hline $1 \mathrm{~A}$ & - \\
\hline $1 \mathrm{~B}$ & - \\
\hline $1 \mathrm{C}$ & - \\
\hline $2 \mathrm{~A}$ & - \\
\hline $2 \mathrm{~B}$ & - \\
\hline $2 \mathrm{C}$ & - \\
\hline $3 \mathrm{~A}$ & - \\
\hline 3B & - \\
\hline $3 \mathrm{C}$ & - \\
\hline $4 \mathrm{~A}$ & $13.6(0.9)$ \\
\hline 4B & - \\
\hline $4 \mathrm{C}$ & $70.0(0.0)$ \\
\hline $5 \mathrm{~A}$ & - \\
\hline $5 \mathrm{~B}$ & - \\
\hline $5 \mathrm{C}$ & - \\
\hline $6 \mathrm{~A}$ & $30.0(1.0)$ \\
\hline $6 \mathrm{~B}$ & - \\
\hline $6 \mathrm{C}$ & $37.8(0.0)$ \\
\hline $7 \mathrm{~A}$ & - \\
\hline $7 \mathrm{~B}$ & - \\
\hline $7 \mathrm{C}$ & $39.0(0.0)$ \\
\hline $8 \mathrm{~A}$ & $15.9(0.1)$ \\
\hline $8 \mathrm{~B}$ & - \\
\hline $8 \mathrm{C}$ & - \\
\hline $9 \mathrm{~A}$ & - \\
\hline $9 \mathrm{~B}$ & - \\
\hline $9 \mathrm{C}$ & - \\
\hline $10 \mathrm{~A}$ & - \\
\hline 10B & - \\
\hline $10 \mathrm{C}$ & - \\
\hline
\end{tabular}

${ }^{a}$ Results are expressed as means (standard deviation) of three determinations. nq, not quantified. could not be detected by the present technique. On the other hand, the fact that each mushroom corresponds to a different individual cannot be excluded. This fact could also explain the presence of $p$-hydroxybenzoic acid in samples $8 \mathrm{~A}$ (entire mushroom) and its absence in samples $8 \mathrm{~B}$ (stipe) and $8 \mathrm{C}$ (cap). This is the first time that $p$-hydroxybenzoic acid is identified in $S$. granulatus species. In addition, quercetin, previously detected (Ribeiro et al., 2006), was not found in this study likely due to the development of the samples.

Other phenolic compounds with absorption maxima around $260 \mathrm{~nm}$ were detected in all of the analyzed species, although it was not possible to identify them.

\subsection{Alkaloids}

The quantification of total alkaloids in the analysed samples revealed that $B$. edulis was clearly the species presenting significantly higher contents of these compounds. In a general way, the three remaining species showed identical amounts of these compounds (Table 4, Fig. 4).

B. edulis exhibited a similar tendency to accumulate alkaloids either in cap or in stipe. The behaviours of the other species were different, since they showed a tendency for higher contents of alkaloids in the cap, this being significant for $R$. cyanoxantha and A. rubescens. The lower alkaloid amounts found in the entire mushrooms of $B$. edulis and $R$. cyanoxantha could be due to some dilution effect and/or to the fact that each mushroom represents a distinct individual.

\subsection{Antioxidant activity}

The antioxidant potentials of the different mushroom materials were evaluated by their $\mathrm{DPPH}^{-}$-scavenging effect, which appeared to be concentration-dependant (Fig. 5). The $\mathrm{IC}_{25}$ values and the percentage of DPPH-scavenging of lyophilized extract at $500 \mu \mathrm{g} / \mathrm{ml}$ were used to compare their antioxidant properties, since it was not possible to calculate the $\mathrm{IC}_{25}$ for $S$. granulatus stipe (Table 5).

For $R$. cyanoxantha species we used sample 2, for which cap was the component presenting the highest antioxidant activity, followed by the entire mushroom and the stipe (Fig. 5). These results do not follow the total organic acids contents order (Table 2). Neverthless, citric acid concentration was considerably higher in the cap and the stipe contained the lowest amount of this acid. These data suggest that citric acid may be important for the antioxidant capacity of the species. The alkaloids could also have a relevant role, since their total contents (Table 4) followed the same order as that of the antioxidant capacity.

A. rubescens species (sample 6) followed this order: entire mushroom $>$ stipe $\gg$ cap (Table 5, Fig. 5). Neither organic acid nor alkaloid contents followed the same order. However, the stipe had a higher organic acids content than had cap and, therefore, it may give a major contribution to the antioxidant capacity. 


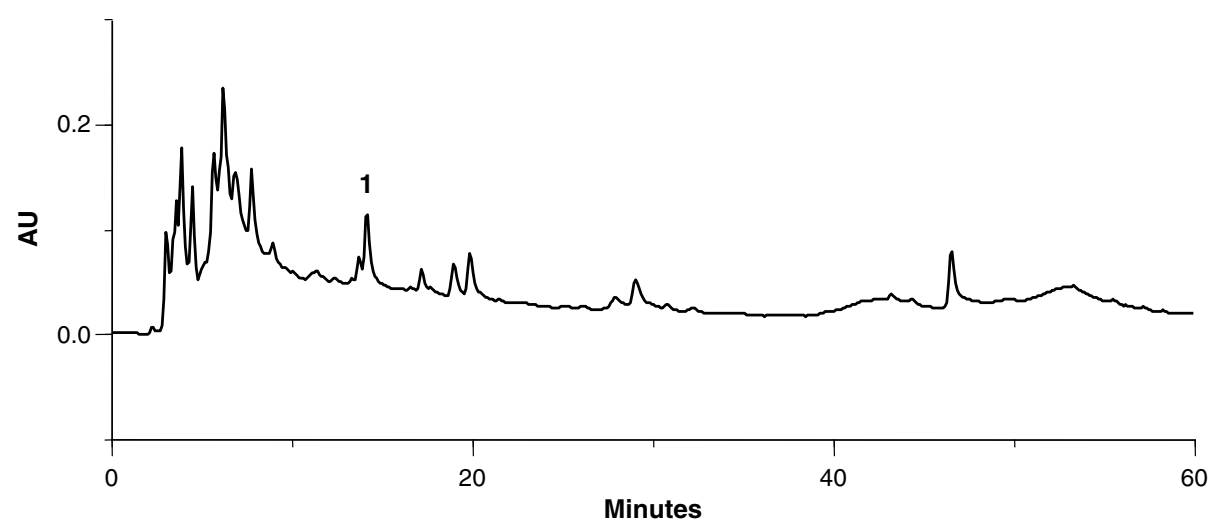

Fig. 3. HPLC phenolic profile of $S$. granulatus entire mushroom (sample 8A). Detection at $280 \mathrm{~nm}$. (1) p-hydroxybenzoic acid.

Table 4

Total alkaloids content of mushroom species $(\mathrm{mg} / \mathrm{kg} \text {. dry basis })^{\mathrm{a}}$

\begin{tabular}{ll}
\hline Sample & $(\mathrm{mg} / \mathrm{kg})$ \\
\hline 1A & $15.1(0.2)$ \\
1B & $5.7(0.1)$ \\
1C & $22.8(1.0)$ \\
2A & $12.3(0.1)$ \\
2B & $5.3(0.1)$ \\
2C & $17.2(1.6)$ \\
3A & $18.2(0.3)$ \\
3B & $5.0(0.2)$ \\
3C & $10.5(0.4)$ \\
4A & $17.0(0.0)$ \\
4B & $6.4(0.1)$ \\
4C & $13.9(0.2)$ \\
5A & $26.6(0.0)$ \\
5B & $6.5(0.2)$ \\
5C & $15.3(0.0)$ \\
6A & $12.7(0.1)$ \\
6B & $6.7(0.1)$ \\
6C & $12.9(0.3)$ \\
7A & $21.7(0.5)$ \\
7B & $6.0(0.1)$ \\
7C & $11.2(0.3)$ \\
8A & $20.7(0.4)$ \\
8B & $5.5(0.1)$ \\
8C & $9.1(0.1)$ \\
9A & $48.2(0.6)$ \\
9B & $91.4(1.7)$ \\
9C & $92.4(1.4)$ \\
10A & $50.0(0.5)$ \\
10B & $96.5(1.9)$ \\
10C & $88.0(0.4)$ \\
\hline & \\
&
\end{tabular}

${ }^{a}$ Results are expressed as means (standard deviation) of three determinations.

The $p$-hydroxybenzoic acid may not be relevant for the antioxidant activity, since it is present in higher amounts in the cap than in the entire mushroom which displayed the weakest and strongest antioxidant effects, respectively. The same conclusion can be drawn about the role of alkaloids, which are present in similar amounts either in the cap or in the entire mushroom (Table 4).

S. granulatus antioxidant potential (sample 8) displayed the same sequence as found for $R$. cyanoxantha: cap $>$

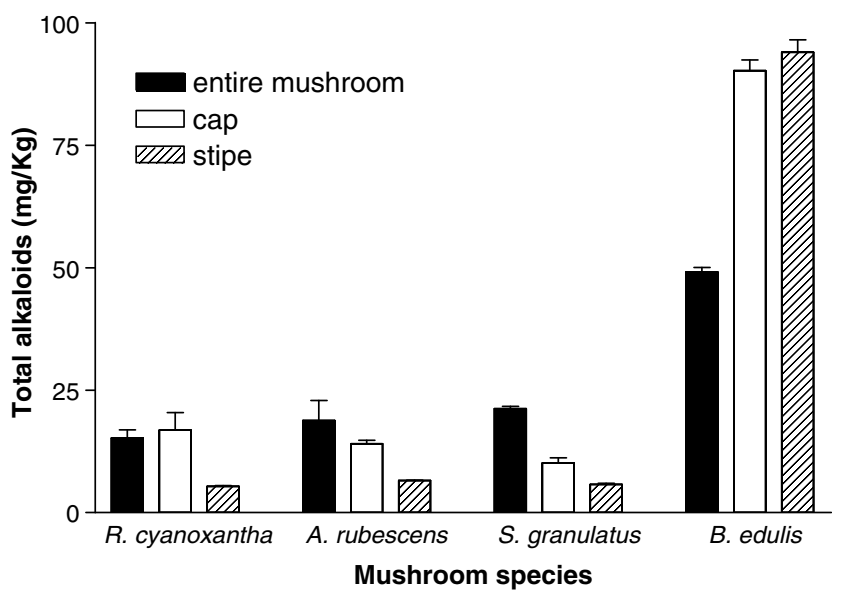

Fig. 4. Total alkaloids content of edible mushroom species. Values represent means and standard error bars are on the top of each column. Values show means $\pm \mathrm{SE}$ from 2 ( $S$. granulatus and B. edulis) or 3 ( $R$. cyanoxantha and $A$. rubescens) experiments performed in triplicate.

entire mushroom $>$ stipe (Table 5, Fig. 5). This order corresponds to that of the total organic acid amounts in the sample (Table 2). In addition, the content of the pair, malic plus quinic acids, follows the order referred to above for the antioxidant activity, suggesting that they may be important for the antioxidant capacity of the species. The relevance of phenolic compounds could not be evaluated, since $p$-hydroxybenzoic acid was detected only in the entire mushroom (Table 3 ). This compound most probably does not play an essential role in the antioxidant activity of $S$. granulatus, as it is absent in the cap, which exhibited the highest potential. Concerning alkaloids, the results showed that the cap exhibited higher total contents and antioxidant capacity than did the stipe (Tables 4 and 5).

To check the antioxidant potential of $B$. edulis species, sample 9 was assayed. The cap displayed the highest capacity, followed by the stipe and entire mushroom (Table 5, Fig. 5). This order suggests that some kind of antagonism could occur between some compounds of the cap and the stipe, in order to decrease the antioxidant potential of the entire mushroom. In addition, the organic acids profile could be responsible, in part, for the antioxidant activity 
R. cyanoxantha

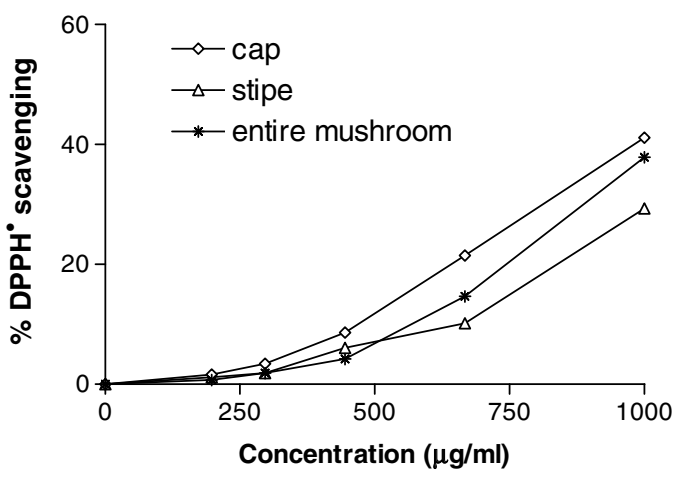

A. rubescens

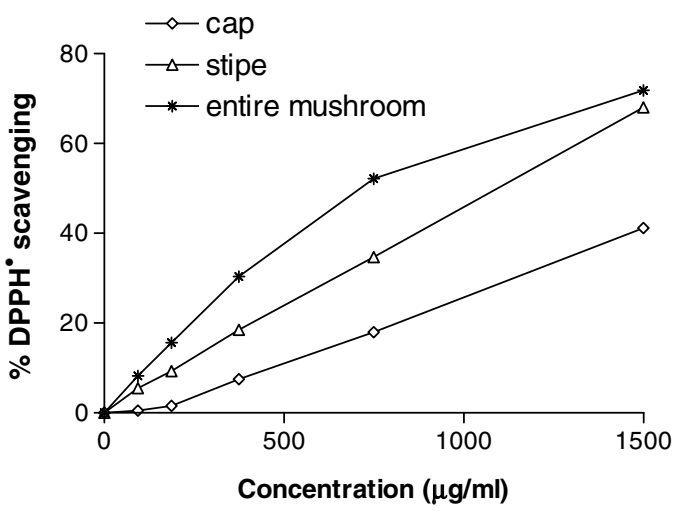

S. granulatus

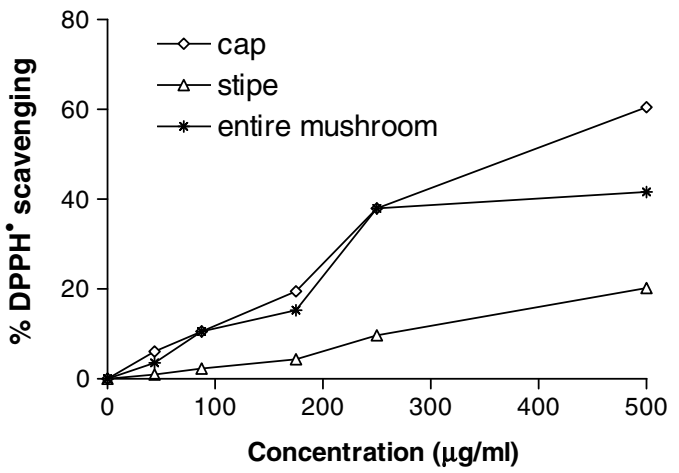

B.edulis

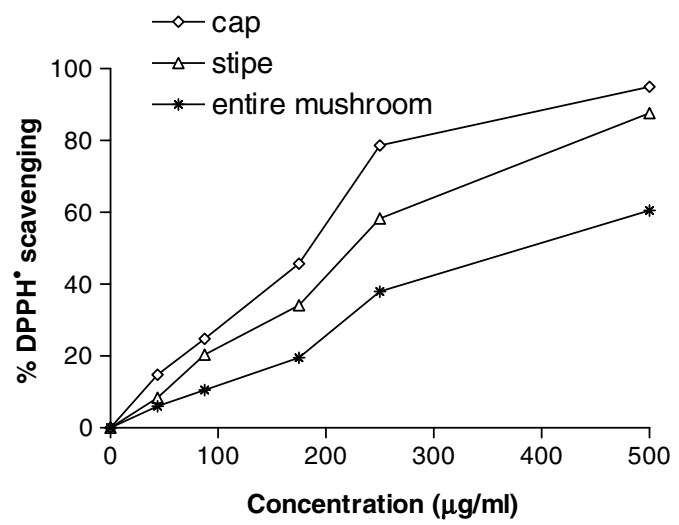

Fig. 5. Effect of the studied mushroom species on DPPH reduction. Values show means \pm SE from experiments performed in triplicate.

Table 5

$\mathrm{DPPH}$-scavenging activity of mushroom species

\begin{tabular}{llc}
\hline Sample & $\mathrm{IC}_{25}(\mu \mathrm{g} / \mathrm{ml})$ & $\%$ Activity $500 \mu \mathrm{g} / \mathrm{ml}$ \\
\hline 2A & 835 & 7.0 \\
2B & 936 & 6.3 \\
2C & 760 & 11.5 \\
6A & 304 & 38.3 \\
6B & 527 & 23.8 \\
6C & 990 & 10.6 \\
8A & 196 & 41.6 \\
8B & - & 20.2 \\
8C & 184 & 60.5 \\
9A & 184 & 60.5 \\
9B & 109 & 87.6 \\
9C & 77.4 & 94.9 \\
\hline
\end{tabular}

of $B$. edulis species, since organic acids total content followed the sequence observed for the antioxidant activity (Table 2). Malic acid accumulated preferentially in the cap which presented the highest antioxidant activity. Thus, it could have an important role in this capacity.

Considering the total alkaloids contents of $B$. edulis and the results obtained in the DPPH-scavenging assay (Tables 4 and 5), the participation of these compounds in the antioxidant activity can be suggested, but their contribution is still not clear. In fact, the contents of both cap and stipe were similar but the antioxidative effect of the cap was higher than that of the stipe.
From an inter-specific point of view, if we compare the entire mushrooms of the different species, we can observe that $B$. edulis clearly presented the highest antioxidant activity, followed by $S$. granulatus and A. rubescens. $R$. cyanoxanthawas the species with the weakest capacity (Table 5). These results are in accordance with those found previously for these species (Ribeiro et al., 2006). Comparing the caps from the different species, the antioxidant potential sequence was $B$. edulis $>S$. granulatus $>R$. cyanoxantha $>A$. rubescens, whereas that for the stipe followed the order $B$. edulis $>A$. rubescens $\approx S$. granulatus $>R$. cyanoxantha. Unequivocally, B. edulis materials were the ones exhibiting higher antioxidant potential within the studied species.

It should be emphasised that organic acids, phenolic compounds and alkaloids composition is insufficient to justify the antioxidant potential of analyzed species. Other compounds must likely also participate in the observed activity.

In conclusion, from the nutritional and health protection points of view, we can say that the four species studied in this work are rich in organic acids, but phenolic compounds are present in very low amounts. Organic acids accumulate preferably in the cap. All analysed species present antioxidant potential, especially high for $B$. edulis, which is also the species richest in alkaloids. Except for 
A. rubescens, it seems that the cap is the material that most contributes to the antioxidant activity of these species. The variety of compounds and the antioxidant potential revealed by the analysed species represent an important contribution to the knowledge of wild edible mushroom species (of great consumption) and their possible beneficial effect for human health.

\section{Acknowledgement}

Bárbara Ribeiro is indebted to Fundação para a Ciência e a Tecnologia for a grant (SFRH/BD/22108/2005).

\section{References}

Bas, C., Kuyper, T. W., Noordeloos, M. E., \& Vellinga, E. C. (19902001). Flora Agaricina Neerlandica: Critical monographs on families of agarics and boleti occurring in the Netherlands (Vol. 1-5). Rotterdam: A.A Balkema.

Bendini, A., Cerretani, L., Pizzolante, L., Toschi, T. G., Guzzo, F., Ceoldo, S., et al. (2006). Phenol content related to antioxidant and antimicrobial activities of Passiflora spp. extracts. European Food Research and Technology, 223, 102-109.

Bon, M. (1988). Guia de campo de los hongos de Europa. Barcelona: Ediciones Omega.

Courtecuisse, R. (1999). Mushrooms of Britain and Europe. London: HarperCollins Publishers.

Courtecuisse, R., \& Duhem, B. (1995). Mushrooms and toadstools of Britain and Europe. London: HarperCollins Publishers.

Marchand, A. (1971). Champignons du Nord et du Midi, Tome 1-9. Perpignan: Soc. Mycol. Pyrénées Mediterranéenes.

Mato, I., Huidobro, J., Simal-Lozano, J., \& Sancho, M. T. (2003). Significance of nonaromatic organic acids in honey. Journal of Food Protection, 66, 2371-2376.

Mattila, P., Könkö, K., Eurola, M., Pihlava, J.-M., Astola, J., Vahteristo, L., et al. (2001). Contents of vitamins, mineral elements, and some phenolic compounds in cultivated mushrooms. Journal of Agricultural and Food Chemistry, 49, 2343-2348.
Mattila, P., Suonpaa, K., \& Piironen, V. (2000). Functional properties of edible mushrooms. Nutrition, 16, 694-696.

Moser, M. (1983). Keys to Agarics and Boleti (Poliporales, Boletales, Agaricales, Russulales). London: Roger Phillips.

Quezada, N., Ascensio, M., Del Valle, J. M., Aguilera, J. M., \& Gómez, B. (2004). Antioxidant activity of crude extract, alkaloid fraction and flavonoid fraction from boldo (Peumus boldus Molina) leaves. Journal of Food Science, 69, 371-376.

Ribeiro, B., Valentão, P., Baptista, P., Seabra, R. M., \& Andrade, P. B. (2007). Phenolic compounds, organic acids profiles and antioxidative properties of beefsteak fungus (Fistulina hepatica). Food and Chemical Toxicology. doi:10.1016/j.fct.2007.03.015.

Ribeiro, B., Rangel, J., Valentão, P., Baptista, P., Seabra, R. M., \& Andrade, P. B. (2006). Contents of carboxylic acids and two phenolics and antioxidant activity of dried portuguese wild edible mushrooms. Journal of Agricultural and Food Chemistry, 54, 8530-8537.

Sreevidya, N., \& Mehrotra, S. (2003). Spectrophotometric method for estimation of alkaloids precipitable with Dragendorff's reagent in plant materials. Journal of AOAC International, 86, 1124-1127.

Tringali, C., Piattelli, M., Geraci, C., \& Nicolosi, G. (1989). Antimicrobial tetraprenylphenols from Suillus granulatus. Journal of Natural Products, 52, 941-947.

Valentão, P., Andrade, P. B., Rangel, J., Ribeiro, B., Silva, B. M., Baptista, P., et al. (2005a). Effect of the conservation procedure on the contents of phenolic compounds and organic acids in chanterelle (Cantharellus cibarius) mushroom. Journal of Agricultural and Food Chemistry, 53, 4925-4931.

Valentão, P., Lopes, G., Valente, M., Barbosa, P., Andrade, P. B., Silva, B. M., et al. (2005b). Quantitation of nine organic acids in wild mushrooms. Journal of Agricultural and Food Chemistry, 53, 3626-3630.

Wasser, S. P., \& Weis, A. L. (1999). Medicinal properties of substances occurring in higher Basidiomycetes mushrooms: Current perspective (review). International Journal of Medicinal Mushrooms, 1, 31-62.

Yang, J.-H., Lin, H.-C., \& Mau, J.-L. (2002). Antioxidant properties of several commercial mushrooms. Food Chemistry, 77, 229-235. 